\title{
Educación moral en Sudamérica: un sistema pedagógico de transversalidad
}

\author{
MIGUEL ANTONIO AHUMADA CRISTI \\ Universidade Federal da Integração Latino-Americana, Foz do Iguaçu, PR, Brasil \\ XUS MARTÍN GARCÍA \\ Universidad de Barcelona, Barcelona, España
}

\section{RESUMEN}

En el presente artículo nos hemos propuesto, primeramente, defender la tesis que la educación moral es la educación en sí. Para ello, nos fue necesario comprender qué es la educación de la moralidad, sus elementos constitutivos y su relevancia en los sistemas pedagógicos. Luego, explicar y comentar el estado de la educación moral en los países del Cono Sur de América, región que ha optado por desarrollar la esfera ética de la educación a partir del modelo transversal. Vale decir, este artículo tiene dos momentos: la construcción de un discurso que nos permita llegar a un entendimiento más o menos acabado del tema, y la descripción y comprensión crítica del modelo transversal, que está muy presente en los países Sudamericanos.

educación moral; modelo transversal; Sudamérica. 


\section{MORAL EDUCATION IN SOUTH AMERICAN: A PEDAGOGICAL SYSTEM OF TRANSVERSALITY}

\section{ABSTRACT}

In this article, firstly, we have proposed to defend the thesis that the moral education is the education itself. For this, it was necessary to comprehend what is the education of morality, as well as its constitutive elements and its relevance in the pedagogical systems. Therefore, we have tried to explain and commented the state of moral education in the Southern Cone of America, region in which a development of the ethical sphere of education from a transversal model is adopted. It's worth to say, this article contains two moments: the construction of a speech that allows us to arrive at a broadly defined understanding about the theme, and the description and the critical comprehension about the transversal model, a very present focus in several southern countries.

KEYWORDS

moral education; transversal model; South America.

\section{EDUCAÇÃO MORAL NA AMÉRICA DO SUL: UM SISTEMA PEDAGÓGICO DE TRANSVERSALIDADE}

RESUMO

No presente artigo temos como objetivo, primeiramente, defender a tese de que a educação moral é a educação em si. Para isso, foi necessário compreender o que é a educação da moralidade, seus elementos constitutivos e sua relevância nos sistemas pedagógicos. Logo, explicar e comentar o estado da educação moral nos países do Cone Sul de América, região que optou por desenvolver a esfera ética da educação a partir do modelo transversal. Este artigo tem dois momentos: a construção de um discurso que nos permita chegar a um entendimento mais o menos acabado do tema e a descrição crítica do modelo transversal, que está muito presente nos países sul-americanos.

PALAVRAS-CHAVE

educação moral; modelo transversal; América do Sul. 


\section{¿QUÉ ES LA EDUCACIÓN MORAL?}

La educación moral es, en sí, la educación misma. Hemos dado una respuesta muy directa a la pregunta del epígrafe, corresponde entonces que la aclaremos y justifiquemos lo más posible.

No en pocas ocasiones la educación moral, llamada también de educación de la moralidad, se entiende como una rama más de la educación en general, desarrollada principalmente en el hogar, con la familia, y en la escuela con los pares y docentes. Es válido pensar que en el seno familiar y en las distintas etapas escolares se presentan los espacios y ambientes donde observamos y/o vivimos nuestras primeras experiencias, reflexiones y conductas morales. Es válida también esta idea porque el simple hecho que nadie nace como sujeto moral, todos y todas nos vamos tornando tales y en ello muchísimo colaboran ambientes como el hogar y el colegio. No obstante, esta manera de entender la educación moral es en parte acertada, pues el precisar únicamente dónde ocurre la educación moral nos conduce solo a una cuestión de lugares y de entornos. Y la esencia de la cuestión va mucho más allá de estos aspectos.

En términos más específicos, la educación de la moralidad se puede comprender como la vertiente de la educación que nos lleva al encuentro con un sistema de valores y virtudes, de costumbres, de ideas y creencias. Sin el contacto con este sistema difícilmente alguien se puede desarrollar como ser humano, en la plenitud del concepto. En este escenario, la educación moral también se comprende como un ejercicio de reflexión y acción que permite al sujeto, desde la niñez y muy probablemente hasta la muerte, construir su personalidad moral a partir de las experiencias o situaciones diarias que afectan o estimulan su reflexión, sus sentimientos y su actuar.

Para precisar el concepto algo más, menester es señalar que la educación moral no solo se da en el ambiente familiar y en el colegio, también en otros espacios de socialización o de acceso a informaciones: en la calle, en el mercado, en fiestas, practicando deportes, en el trabajo, leyendo el diario o escuchando noticias, con los amigos, compartiendo con el pueblo. Yendo más lejos, es posible sostener que es en estos ambientes y espacios donde ocurre, con más belleza y sabiduría, lo que Paulo Freire y Frey Betto (1986) en una oportunidad llamaran de Esa escuela llamada vida. Es en esta escuela donde aprendemos, a partir de los saberes populares socialmente compartidos, a vivir. Este es precisamente el fin último de la educación: saber vivir, con uno mismo y con los demás, i.e., vivir en la esfera individual, privada y en la social. Y aprender a vivir con todo lo que aquello involucra, v.g., los aciertos y alegrías, los errores y la reflexión, lo lúdico y las obligaciones, los sueños políticos y los anhelos de mundo (Torroella, 2001).

En razón a lo dicho hasta esta parte, podemos definir de manera provisoria la educación de la moralidad:

- La educación moral es un ejercicio de construcción que se hace posible en cualquier espacio y ambiente que nos remita a un sistema de valores y que, posibilitando el desarrollo de la personalidad moral, favorece que aprendamos a vivir. 
Presentaremos las posibilidades de esta definición, y para ello consultaremos a algunos especialistas. Aclaramos, de todos modos, que por razones de espacio nos centraremos en la idea que la moralidad es un ejercicio de construcción, tesis que iremos enriqueciendo mientras avancemos. De acuerdo con Puig, la educación de la moralidad es

una tarea encaminada a dar forma moral a la propia identidad mediante un trabajo de reflexión y acción a partir de las circunstancias que cada sujeto va encontrando día a día. Pero se trata de un proceso de construcción que nadie realiza de modo aislado, sino que cuenta siempre con la ayuda de los demás, así como de múltiples elementos culturales valiosos que contribuyen activamente a conformar la identidad moral de cada sujeto. (Puig, 1996, p. 14)

Esta definición de Puig nos pone en el primer punto de inflexión de nuestro diálogo: la construcción del sujeto moral depende de su contacto con los demás y de los elementos culturales de su entorno. Esto es acertado, y veremos el porqué desde lo más básico a lo más complejo.

La educación de la moralidad se puede entender como una más de las múltiples esferas de la educación, como lo es la intelectual, la artística y la corporal, pero se diferencia de todas estas por el simple hecho que quiere, nada más ni nada menos, "dar sentido y dirección al ser humano en su conjunto". Como señala Puig (1996, p.10), "es una dimensión formativa que atraviesa todos los ámbitos de la educación y de la personalidad".

En este contexto, el sujeto que construye su moralidad nunca deja de depender - aunque por ahora no sabemos hasta qué punto - de la esfera social, i.e., los otros y las reflexiones o prácticas morales, y del entorno cultural, v.g., las artes y los medios de comunicación masivos, entre otras cosas. Y es debido a estos problemas que la educación moral constituye el aspecto central de la formación humana: se ocupa del saber vivir, especialmente en la construcción de quién luego de la niñez será un ciudadano o ciudadana (Dewey, 1934).

Pensaremos ahora si realmente la educación moral depende del contacto con los otros. Aparentemente, y por sentido común, sí. Pero esto debemos ensayarlo, aunque sea en un breve espacio. De acuerdo a Gadamer (2002), todo sujeto se construye en ambientes de socialización, no obstante, el arraigamiento de la moral depende del propio individuo: "educar es educarse”, decía el filósofo. A este fenómeno se suele llamar de desarrollo de la autonomía moral, otro de los fines importantes de la ética y de la educación. No obstante, lo que no tenemos por dónde desconocer, es que la educación de la moralidad también se trata de un proceso en que el ser, volcado a la otredad, adquiere y construye virtudes o valores que pasarán a orientar su vida, i.e., educar también es educarse a partir de los otros, en relación con estos. Este último fenómeno al parecer no definitoriamente, sino como una cuestión procesual inacabada de adaptación a un medio que continuamente cambia.

A pesar de lo dicho, el asunto es más complejo. No basta con el mero ejercicio de acomodo, pues el adaptarse a cualquier cambio o transformación social requiere 
de ejercicios de reflexión (Puig, 1996, p. 15). Esto último sí nos lleva directamente a pensar que el proceso de adaptación debe ser crítico, pues la transformación de la persona en un ser moral es finalmente un proceso educativo que busca la autonomía, el autonombrarse. Como pensaba Kant (2000), pensar y construirse críticamente y a partir de uno mismo, pues si los procesos de influencia y coerción externa al individuo dominan o influyen totalmente su moralidad, el sujeto no construye de manera autónoma su personalidad moral y se transforma en una persona determinada por el ambiente y las pretensiones externas a su individualidad. En este contexto, la sociedad y sus cambios constituyen al sujeto, el sujeto no tiene la posibilidad de educarse por sí mismo.

Otro autor que se refiere a la educación moral en términos de construcción es Yves de La Taille. El profesor La Taille fundamenta sus ideas sobre cómo deberíamos construir nuestra personalidad moral a partir de las tesis de Kant sobre el orden en que el sujeto debe actuar moralmente: el imperativo deber-ser y la protección racional de la dignidad como ejes articuladores del saber hacer el bien (La Taille, 2012, p. 105-114). Pensaba el propio Kant que "lo que importa, sobre todo, es que el niño aprenda a pensar. Que obre por principios, de los cuales se origina toda acción" (Kant, 2000, p. 19). Amén a esta idea, La Taille comprende la educación moral como una acción consciente que más que hacer el ejercicio de enseñar y aprender formas de actuar, debe promover que el sujeto aprenda a reflexionar, descubrir y construir "en nombre de qué" o "bajo qué principios imperativos debe actuar". La visión de La Taille, al cargarse de matices kantianos, se torna un tanto formal; o bien, de una educación moral deóntica, es decir, motivada por educar el deber y los principios. ${ }^{1}$ No obstante, el psicólogo también entiende que no debemos descuidar el carácter práctico de la vida moral del ser, esto es, los modos de hacer el Bien, su carácter útil y el deseo de felicidad (Aristóteles y su visión teleológica), como también su dimensión afectiva: la relación sentimental con los seres y cosas que habitan el mundo. En síntesis, La Taille piensa que tanto que el "saber hacer el bien", es decir, saber realizar una moral virtuosa, viene determinada por la combinación entre el deber-ser, la felicidad y el ámbito afectivo.

En línea con Puig y La Taille, Martínez y Tiana defienden una pedagogía axiológica en donde no se eduque mediante "los reduccionismos que hacen los planteamientos enciclopédicos de educación en valores" (Martínez y Tiana, 2004, p. 11). Para ello, estos autores proponen trabajar la dimensión ética de la educación a partir de acciones que estimulen en los alumnos y alumnas no solo el conocimiento, también las actitudes y las formas de actuar. En donde los profesores faciliten la apreciación y comprensión crítica de los valores, y en donde la intersubjetividad de los discentes permita comprender qué valores bien favorecen la convivencia y las interrelaciones. Se trata no de un encauzamiento a valores meta preestablecidos y

1 Nos dice Kant que el deber constituye una garantía formal de universalidad, lo que en definitiva permite fundamentar nuestras acciones en principios. Como lo apunta en su teoría moral y pedagógica, no se trata de una imposición y sí de una forma para descubrir principios universales que orienten categóricamente nuestra acción (Kant, 2003). Ese es el sentido de base, pero a la vez el más profundo, del aprender a pensar kantiano. 
definidos, sino de la oportunidad de descubrir y construir qué valores favorecen el bienestar social en su conjunto (cohesión). A juicio de Martínez y Tiana, si algo se ha de posibilitar objetivamente, es el cultivo de una disposición reflexiva y sentimental que permita a los alumnos implicarse en proyectos colectivos, valorar la responsabilidad social y la participación ciudadanía como elementos que podrían asegurar una convivencia equitativa, justa y solidaria.

Si nos detenemos un instante, fácilmente podemos percibir que hemos llegado a otro estadio de la educación moral: el sujeto que será ciudadano. Entonces, producto de su carácter cohesivo del conocimiento y de los bienes humanos, la formación de la moralidad es también un proceso de formación ciudadana, en el sentido de colectividad y participación. Y la ciudadanía, como bien lo expresa Machado es

la construcción de instrumentos legítimos de articulación entre proyectos individuales y proyectos colectivos. [Y educar para la ciudadanía es] proveer a los individuos de instrumentos para la plena realización de esta participación motivada y competente, de esta simbiosis entre intereses personales y sociales, de esta disposición para sentir los dolores del mundo. (Machado, 2004, p. 42-43)

Trátase, por cierto, de una educación de la moralidad en línea con una política de desarrollo y protección de los deberes y derechos ciudadanos.

Los argumentos anteriores, hasta aquí, parecen validar implícitamente nuestra respuesta a la pregunta ¿qué es la educación moral? pues es la propia educación. Para estar más seguros, vamos a ver si tal aserto puede justificarse desde otra fuente: estudiando el concepto educación, término que pensamos no se puede pensar, jamás, por separado de la moralidad. Veamos entonces.

Hay dos versiones sobre el origen del sustantivo educación. La primera sostiene que proviene del latín educatio; la otra, indica que la voz más primitiva de este vocablo es ex-duco, que significa extraer desde dentro hacia afuera las capacidades del ser humano y potenciarlas mediante un acto guiado (Quinteros, 2005, p. 12). Desde otro ángulo, la educación se lleva a cabo mediante un acto: "educar". Este verbo tiene como base dos conceptos en latín, educere y educare, y si bien literalmente ambos significan lo mismo (instruir, formar, inculcar) se les otorga un sentido distinto (Del Col, 2007). El primero, adquiere la misma dirección que ex-duco, extraer desde dentro del individuo los conocimientos que este posee para que luego de un acto guiado por sí mismo los logre optimizar. Se trata de encauzar al educando hacia el logro más perfecto de sus potencialidades. A su vez, educare adquiere el sentido de transmitir o inculcar conocimientos y técnicas a una persona que a priori no las posee (Romão, 2005, p. 33). Sabemos que ambos sentidos son necesarios y forman parte de casi todos los sistemas formales o coloquiales de educación. Hay cosas que hombres y mujeres no saben, sobre todo en edades menores, y que es necesario enseñarles (educare), y otras de las que ya tienen conocimientos y menester es guiarlos a descubrirlos y a optimizarlos (educere); o bien, posibilitar aquello. Este último sentido, a diferencia del primero, favorece que se creen o se llegue a cuestiones antes impensadas. 
Ahora bien, fuera del ámbito etimológico, la educación generalmente se suele entender a partir de dos ideas. La primera, que es la "transmisión y el aprendizaje de las técnicas culturales"; la segunda, indica que es un proceso inacabable de adquisición de conocimientos y de prácticas (Abbagnano, 2007). Si complementamos y ampliamos ambas ideas, podemos entender que la educación es un proceso sinza fine mediante el cual se transmiten y se adquieren, o también se transforman o se crean, informaciones que se tornan conocimientos y acciones (Puig, 1996, p. 14). Esto accede a que se aprendan y se perfeccionen los saberes y las prácticas que forman una cultura, i.e., los modos de vivir y de pensar cultivados históricamente y que favorecen la formación moral, intelectual, corporal, afectiva y artística de hombres y mujeres, su corrección y progreso.

En estricto rigor, la educación es lo que hace posible que nuestra especie como la conocemos no se extinga. Aquello, porque es imposible que una nueva generación sobreviva si la anterior no le transmite los saberes necesarios para subsistir (Abbagnano y Visalbergui, 1992). Este fenómeno se puede observar desde la belleza cultural de los pueblos originarios hasta en los aciertos y en las torpezas de las sociedades civiles que nos preexisten y en las cuales vivimos.

En cuanto a cómo los saberes culturales se transmiten, suelen ser dos las formas más practicadas: los conocimientos se traspasan generacionalmente de manera absoluta, es decir, como cuestiones inmutables — que en cuanto a valores y actitudes es el arquetipo de las sociedades fundamentalistas - ; o bien, se transmiten conocimientos y prácticas con el fin que estas sean dentro de lo posible, y si es posible, rectificadas y mejoradas. A diferencia de la primera, esta forma puede posibilitar la libertad y la creatividad de las personas.

Desde otra perspectiva, debido a los avances progresivos de la ciencia y de la tecnología, y a los rápidos y constantes cambios culturales y sociales - especialmente los del último siglo - la educación ya no se vio solo como un proceso de adquisición, transformación o creación de saberes, también de adaptación a un medio que muda permanentemente. En este contexto, la educación es valorada como una actividad para toda la vida, pues se refiere a la realización de los hombres y de las mujeres como seres humanos en la plenitud del concepto, y en esta plenitud se destaca bastante la capacidad adaptativa, trasformadora y creativa del ser humano (Kilpatrick, 1971; Vargas, 2017).

Pues bien, si conjugamos lo que hasta esta parte hemos dicho, nos es posible perfeccionar y hacer algo más completa nuestra definición de la educación de la moralidad.

- La educación moral es un ejercicio de construcción que se hace posible en los espacios y ambientes que nos remiten a un sistema de valores y que, posibilitando el desarrollo de la personalidad moral, favorecen que aprendamos a vivir de manera autónoma y responsable, en la esfera individual, privada y en la pública (la ciudadanía).

Para cerrar este apartado, volvemos a un punto importante y que ya hemos mencionado: que la educación tiene un carácter multidireccional, en el sentido que procura consolidar distintas metas. En la educación formal, que es aquella que posee 
una organización curricular y es impartida especialmente por colegios, institutos o universidades, posee este carácter debido a que no persigue un único fin, sino varios. Esto, debido a que cada disciplina tiene sus propias metas. Por ejemplo, en cierto colegio uno de los objetivos de la educación musical es que los alumnos aprendan a leer una partitura; uno de la educación física, que cultiven el hábito de practicar un deporte. Siendo así, las demás áreas también tienen fines particulares, cuyos ejes, prácticas y metas dan forma a lo que se llama de "esferas formativas". Dentro de estas, se encuentra la corporal, la intelectual, la artística y también la moral. Pues ahora hemos llegado a la pregunta clave y que da origen al segundo apartado: ¿qqué rol cumple esta última esfera, o bien, de qué manera debemos entenderla de modo de asegurar que la educación tiene un fondo moral innegable y necesario?

\section{EDUCACIÓN = EDUCACIÓN MORAL}

Esta ecuación, de hecho, no es algo que hayamos ahora descubierto. La idea que la educación tiene como pilar la adquisición de hábitos morales, o costumbres sociales, es tan antigua como el ser humano, al menos desde la antropología esto se puede demostrar fácilmente. Pero aquí solo nos vamos a remitir al siglo XX. Según Benjamin (1993), durante la primera mitad de este siglo, fue tomando fuerza la idea kantiana (cuyo origen está en Rousseau) que la educación consiste en un "proceso humanizante", en el sentido de hacer noble al sujeto mediante el cultivo de la "buena voluntad". En otras palabras, se comenzó a sostener que la meta final del proceso educativo es humanizar lo más posible a la persona mediante el conocimiento, la razón y la técnica. No obstante, poco a poco, se comenzó a entender que esta idea, por sí sola, se torna insuficiente en los sistemas formales de educación al descuidar el carácter afectivo del ser, es decir, cómo los sentimientos y las emociones afectan parte de su razonamiento moral, y viceversa. En efecto, algunos pensadores postmodernos, en donde se destaca la figura de Richard Rorty, pusieron especial atención en educar la moralidad a partir de la educación afectiva o del sentimiento. En tal sentido, Rorty toma como argumento la vía humana de adquisición de saberes morales; esto es, que la moralidad tiene origen y se construye a partir de los sentimientos, más que por la razón. Dice el propio Hume:

Extinguid todos los sentimientos y predisposiciones entrañables a favor de la virtud, así como todo disgusto y aversión con respecto al vicio; haced que los hombres se sientan indiferentes acerca de estas distinciones, y la moral no será ya una disciplina práctica ni tendrá ninguna influencia en la regulación de nuestras vidas y acciones (Hume, 2006, p. 37).

Los sentimientos, como dimensión reguladora de la moralidad, llevó a Rorty a entender que la educación moral debe ser aquella que promueva el desarrollo de la sensibilidad ética: mostrarle al alumno aquello que humilla al mundo, de modo de concientizarlo o ponerlo en conocimiento de aquellas situaciones que infringen dolor a los seres humanos, donde quiera que sea y sin importar la comunidad o la cultura (Rorty, 1991, p. 210). En primera línea, se encuentra el respeto y el cuidado 
del prójimo como realización de la virtud de la solidaridad y de un enraizamiento de una ética del cuidado: no humillar y afectarse sentimentalmente con la humillación. En consecuencia, para Rorty se debe educar bajo el principio de construcción de una ética solidaria, i.e., de proteger la dignidad de los demás. Y para ello cree necesario actuar sobre la sensibilidad moral de los estudiantes, entendiendo el bien bumano no como una cosa que viene desde el "ego", de personas "como nosotros" o de "los demás", sino desde un "nosotros" (Rorty, 1991, p. 229-230).

En conexión con esta idea están Hoyos y Ruiz, para quien la educación tiene el deber moral de educar la solidaridad, que a su juicio viene a ser la virtud que mejor responde a las necesidades humanas. Pero su realización nunca debe ser asistencialista, sino como un puente para el desarrollo humano y para la igualdad social (Hoyos y Ruiz, 2008, p. 157-158).

Pero ¿qué nos dicen todas estas cosas? En primer término, que, si bien la educación se puede entender como un proceso de trasmisión, de adquisición y posiblemente de transformación de saberes y de técnicas culturales, esto de modo alguno puede alejarse de la orientación valorativa, y dicho acomodo no solo tiene una dimensión racional y práctica, también cumplen un rol importante los sentimientos (Quintana, 2005).

Yendo directo al vínculo íntimo entre educación y educación moral, y considerando que en la moral siembre hay valores de por medio, nos dice Quintana (2005, p. 2.016): "la conexión entre educación y educación en valores comienza con el hecho que la educación implica una referencia esencial a los valores". Lo que este autor desea significar, es que no se puede hablar de educación sin referirnos a valores morales, puesto que, con la intención de dar dirección y sentido a la humanidad del ser, necesariamente la educación requiere de una fuente moral o axiológica.

En este mismo orden, Ortiz señala que la educación es

aquella actividad cultural que se lleva a cabo en un contexto intencionalmente organizado para la transmisión de los conocimientos, las habilidades y los valores que son demandados por el grupo social. Así, pues, todo proceso educativo está relacionado con los valores. (Ortiz, 2003, p. 70)

Similar idea es presentada por Payá et al.:

es redundancia hablar de educación y de educación en valores, dado que la finalidad última de todo proceso educativo es la optimización de la persona, y en la concreción de lo que se entiende por optimización y lo que no se entiende por optimización, debemos recurrir, invariable y necesariamente, a algún fondo axiológico o sistema de valores (Payá et al., s/p.).

En pocas palabras, para todos estos autores la educación y la moral, por extensión los valores, no se pueden entender como cuestiones segregadas, pues se cristalizan en una única expresión: educación-moral, la que invariablemente nos lleva al encuentro con un sistema de valores. En síntesis, el estado de la cuestión es tal y como la expresa Reboul (1986, p. 93): "la educación moral es, nada más y nada menos, la propia educación". 


\section{LA EDUCACIÓN DE LA MORALIDAD EN SUDAMÉRICA}

Entendida la educación como una acción humana cuyo carácter constitutivo esencial son los valores, corresponde que ahora veamos cómo la educación moral se acostumbra a llevar a cabo en esta parte de la región, retratando, aunque sea de manera superficial, las prácticas pedagógicas más comunes de la educación moral. Y para ello hemos optado por describir los niveles preescolar y primer ciclo de enseñanza básica.

Cuando se trata de cuestiones o problemas sociales, es visible que de un país a otro se repiten varias ideas y prácticas. En efecto, en muchas repúblicas del Cono Sur de América Latina existen instituciones educativas que llevan la moral al aula mediante los llamados "programa de valores" o "plan de virtudes". Se trata de prácticas sistematizadas, puesto que un determinado colegio lleva a las salas de clases un número reducido de virtudes que se estiman son las más propicias para que los y las estudiantes convivan de manera adecuada. Las instituciones deciden qué virtudes se han de tratar, cuáles son sus mejores fundamentos, cómo se deben trabajar en clases, en el recreo, y qué rol deben cumplir los profesores en su práctica y enseñanza y los alumnos en su reflexión y práctica para el aprendizaje. La verdad es que son propuestas interesantes y fáciles de llevar a cabo, pero su problema es que, a pesar de elaborar un discurso sobre la autonomía, buscan encauzar al alumno al logro de una moral previamente estimada. Más que de educación, corresponde a esta práctica el concepto de "instrucción". Veamos entonces.

En Brasil, en la educación infantil, aunque extendiéndose a veces hasta el cuarto año y enseñanza básica, se acostumbra educar la moral de los niños y niñas mediante los famosos "combinados", 2 que son un conjunto de reglas pactadas al inicio de cada año entre docentes y discentes, que se supone los estudiantes deben respetar y cumplir para favorecer un ambiente adecuado de socialización, dentro de la sala y fuera de ella. El objetivo es que estas normas de contenido estrictamente valorativo lleguen a ser un hábito, o en el sentido clásico, una virtud. Este catálogo de normas, cuyo diseño contiene imágenes y oraciones, suele colgarse a un costado de la pizarra, de modo que todos los estudiantes puedan observarlas día a día y clase a clase. Y se supone que deben tener un seguimiento, puesto que los o las docentes deben procurar, sea mediante el diálogo o la inducción, que los y las discentes las cumplan (Zaraya, 2013).

En Chile, Argentina y Uruguay, y en otros países de Sudamérica, a esta práctica se le llama comúnmente de "normalización", y se utiliza para referirse al proceso de adaptación del alumno a las reglas de la escuela.

Ahora bien, si evaluamos estos métodos debemos hacerlo con cuidado. Nos parece muy valioso y necesario que los alumnos adquieran hábitos o reglas comunes que suelen favorecer la convivencia. Sería torpe de nuestra parte creer que la vida social no requiere de ciertas normas comunes. Sin embargo, tales métodos podrían errar si caen en el fenómeno de la heteronomía moral y en la mecanización del proceso de aprendizaje de las normas.

2 A veces también se les llama de "regrinhas". 
Si bien en el plano social toda norma funciona como regulador moral, en un ambiente donde todo está determinado, y donde se piensa que todos pueden aprender de la misma forma, no habrá muchos espacios para amparar las diferencias y para crear nuevas cosas. Por tal motivo, hay que cuidar que estas prácticas no se tornen en extremo rígidas e unilaterales, pues podría suceder que para algunos niños y chicos lleguen a ser incluso tiránicas, tanto para el que se las aprende y las exige duramente a los demás, como para aquel que no las comprende y no las cumple. La escuela no puede ser una sociedad donde existan niños que cumplan el rol de policías que juzgan quienes son los bandidos.

La mecanización excesiva del uso de combinados - ese intento de meter las reglas en la conciencia del estudiante - en vez de entenderse como una práctica constructivista, dialógica, de principios y no de duras reglas, ha generado que estos no surtan los efectos necesarios, pues mayoritariamente, como lo expresa Zaraya, a pesar del uso común de los combinados "los niños, dentro del colegio, se ven en un ambiente hostil, intolerante a las diferencias, con valores distorsionados y sin espacio para conversar respecto de sus percepciones" (Zaraya, 2013, p. 14). De acuerdo con La Taille (1996), prácticas como los combinados, si son enseñados de manera mecánica y absoluta, pueden terminar inhibiendo la capacidad del ser humano de resolver conflictos colectivamente, pues los alumnos se basan en reglas continuas y no en principios discutibles, en nuevos pactos o en soluciones creadas en la colectividad.

\section{LA EDUCACIÓN-MORAL EN EL CURRÍCULO ESCOLAR}

A veces los planes de virtudes y los combinados se extienden hasta la educación media (sobre todo en los colegios religiosos); sin embargo, desde quinto básico al último año de enseñanza media la práctica que más ha ganado espacio curricular en América Latina es que la educación de la moralidad se realice de manera transversal a todas las áreas. ${ }^{3}$ Vale decir, que los profesores ajusten temas o problemas de carácter moral y social con relación a los contenidos específicos de las disciplinas que imparten (Araújo, 2003). Estos temas deben ser discutidos por el grupo mediante la coordinación del docente, quien tiene la misión de favorecer el raciocinio crítico, la expresión de los sentimientos y el dominio de las emociones. Este profesional también debe posibilitar la realización de actitudes, ideas, sentimientos o valores vitales como la prudencia, la tolerancia, la justicia, la empatía, la solidaridad, el amor, la democracia y la pluralidad. Convergemos bastante con esta práctica, puesto que hace permisible que en los contenidos de cada disciplina el conocimiento también sea tratado desde una perspectiva ética o sobre la discusión de problemas sociales.

No obstante, existe una crítica común a la propuesta de los temas transversales, y es que se centran demasiado en cultivar una actitud democrática y participativa en los alumnos en consideración apenas de su medio social más cercano. Esta visión,

3 Conferir: Colombia (1998); Oraisón (2000); Perú (2005, p. 22); Fernández y et al. (2008); Chile (1998); Brasil (1997). 
en parte acertada, descuida la inclusión de cuestiones "comunes" a la humanidad. Pérez de Cuellar (1997) indica que la transversalidad debería además sumar problemas universales como: protección de las minorías, igualdad social, democracia y sociedad civil, derechos humanos y responsabilidades morales y políticas, justicia y solución pacífica de conflictos. Nosotros, si bien estamos a favor de educar la moral mediante temas transversales, claro que no como la única opción, nos parece que a la par que preocuparnos de qué temas vamos a trabajar, es necesario importarnos de cómo debemos trabajarlos, bajo qué ambientes y en consideración de qué ideas y de qué objetivos. ¿Por qué? Muy simple, porque el concepto universalidad muchas veces, en vez de adoptar un carácter incluyente, se torna excluyente al no considerar, por ejemplo, la sabiduría de etnias minoritarias e históricamente oprimidas, como lo son los pueblos originarios de América Latina. No en pocas ocasiones el concepto "universalidad" no es más que un símbolo del racionalismo eurocéntrico (Osorio y Balbuena, 2013; Soto, 2012).

En este escenario, conviene que destaquemos el área de educación cívica. En casi todos los países de América Latina y el Caribe el civismo o ciudadanía es una sub área de las asignaturas de historia, geografía o ciencias sociales. Y entre sus objetivos principales se destacan: que los alumnos desarrollen el sentido ciudadano, esto es, que conozcan y comprendan cuáles son sus deberes y derechos en virtud de la vida en democracia y de la pluralidad; que desarrollen una actitud de respeto hacia la diferencia, y de solidaridad en la necesidad. En síntesis, que sepan actuar adecuada y virtuosamente en los espacios de participación ciudadana. La historia y la geografía son tratadas y pensadas para posibilitar la realización futura de estos principios cívico-morales.

Por último, nos resta abordar el denominado "currículo oculto". En toda institución escolar existe el currículo "oficial" o formal, y el "oculto" o informal. En términos globales, el currículum oficial es aquel que, junto al llamado proyecto educativo, dispone los contenidos, objetivos, dinámicas pedagógicas y metodologías que favorecen el proceso de enseñanza y aprendizaje (Sacristán, 2010). El currículo oculto no se refiere a algo que no se ve, sino a aquello que puede entenderse como implícito al "oficial" y que hace referencia a las relaciones sociales que se dan en la escuela. Entonces, este currículo no adviene de una determinada disciplina, sino que se manifiesta en las relaciones humanas. En términos concretos, proyecta las normas, creencias, costumbres, valores, que ejercen influencia en el comportamiento y desarrollo moral de los estudiantes, en sus relaciones los unos con los otros (Jackson, 1992). ${ }^{4}$

En estas relaciones suelen surgir conflictos, sobre todo en niños pequeños y adolescentes. Pues en estos casos, en la cultura escolar, el "currículo oculto" sirve para sacar provecho de estas circunstancias que muchas veces emergen de manera

4 La obra de Jackson (1992), La vida en las aulas, va mucho más allá de lo que hemos apuntado. Incluye, por ejemplo, un estudio del currículum oculto a partir de variados espacios de socialización que son producidos por la "vida escolar": las tareas de escuela (muchas veces hechas con los padres), las exigencias de responsabilidad, de participación, etc. Recomendamos la lectura de este excelente texto. 
espontánea (Araújo, 2003). Sacar provecho moral de estas situaciones no es un problema en sí, sino el cómo obtenerlo. En razón de esto, este método nos parece valioso y arriesgado a la vez. Valioso, porque puede permitir que los alumnos tomen conciencia de los "errores" que cometen en su relacionamiento; arriesgado, por dos cosas:

1. Se puede tornar demasiado dependiente, y ello le da un carácter emergencial. Vale decir, habrá educación moral con intervención adulta solo cuando surja un "error", un "mal comportamiento", v.g., que Juanito pelee a puñetazos con Pedro.

2. Esta práctica a veces tiende a resolver los problemas públicamente, posibilitando que los sujetos involucrados sean sometidos a juicios colectivos, de los docentes y de sus pares.

El profesor y los alumnos deben estar plenamente conscientes de qué elementos racionales, afectivos y emocionales son necesarios para hacer un buen juicio y para llegar a decisiones justas. Esta práctica exige una constante y excelente preparación para llevarla a cabo. Sí creemos en la necesidad de fomentar el juicio crítico desde las primeras etapas de la enseñanza, pero tenemos serias dudas si puede o debería ser bajo el dominio del "currículo oculto".

Volviendo al punto central de esta parte de nuestro diálogo, ya hemos mencionado que las naciones de Sudamérica han llevado el enfoque transversal a sus currículos escolares. No obstante, es bueno decir que se trata de una orientación formalmente enunciada, puesto que no tiene un carácter imperativo. El currículo transversal estipula que no se debe reducir la pedagogía solo a la enseñanza de contenidos, sino incorporar a los contenidos temas o problemas sociales de carácter moral y político. El objetivo final de esta práctica es que el alumno, al relacionarse dialógica y dialécticamente con los otros, progrese en la construcción de su autonomía, tornándose un ciudadano reflexivo, crítico, participativo y responsable.

Y con relación a su práctica cotidiana, según Araújo (2003, p. 107), la transversalidad se aplica a partir de "temáticas específicas relacionadas a la vida cotidiana de la comunidad, a la vida de las personas, a sus necesidades y a sus intereses". Son en el fondo problemas sociales que afectan a todo el grupo y que en el transcurrir de la clase, e independiente del contenido que se trabaje, deberían tener un espacio para ser abordados. En Brasil, entre estos temas es posible encontrar: medio ambiente, salud, consumo, sexualidad y drogadicción. Desde otro ángulo, Moreno entiende los temas transversales como aquellos que posibilitan la formación de personalidades autónomas, críticas, que respetan los argumentos ajenos en tanto defienden los suyos. En tal sentido, son

instrumentos necesarios para obtener las finalidades deseadas — la paz, igualdad de derechos y oportunidades para hombres y mujeres, preservación y mejora del medio ambiente, por una vida más saludable, por el desarrollo de la afectividad y de la sexualidad que permita mejorar las relaciones interpersonales - . (Moreno, 1999, p. 36-37) 
Hemos creado un gráfico sobre el currículo transversal (Gráfico 1).

Para dar más fuerza a la propuesta transversal, algunos autores piensan que es necesario invertir su orden. Por ejemplo, para Araújo (2003) en el currículo y en la práctica estos temas deberían tener un giro radical: los colegios deben estar primero focalizados en la formación valorativa y luego abrir la puerta a los conocimientos científicos de cada disciplina. En otras palabras, para este autor la moral debería esquematizarse y ponerse en práctica de manera vertical, como si fuera el permanente hilo conductor de todas las áreas de la educación. Una idea que a pesar de sus nobles intenciones no es más frecuente que la versión anterior (su horizontalidad). Hemos creado un gráfico sobre esta propuesta (Gráfico 2).

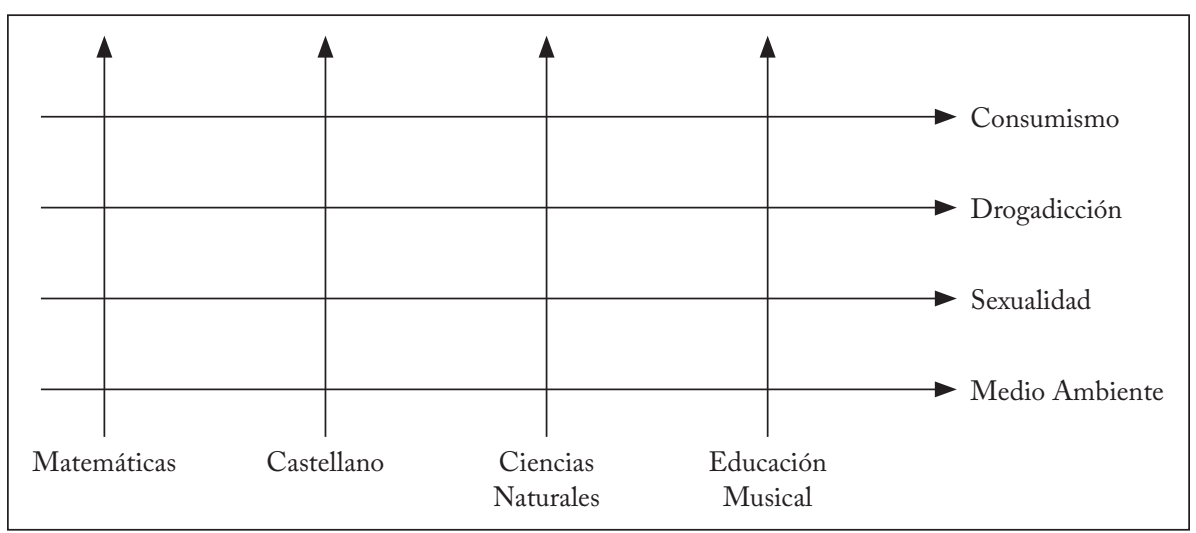

Gráfico 1 - Currículo transversal

Elaboración de los autores.

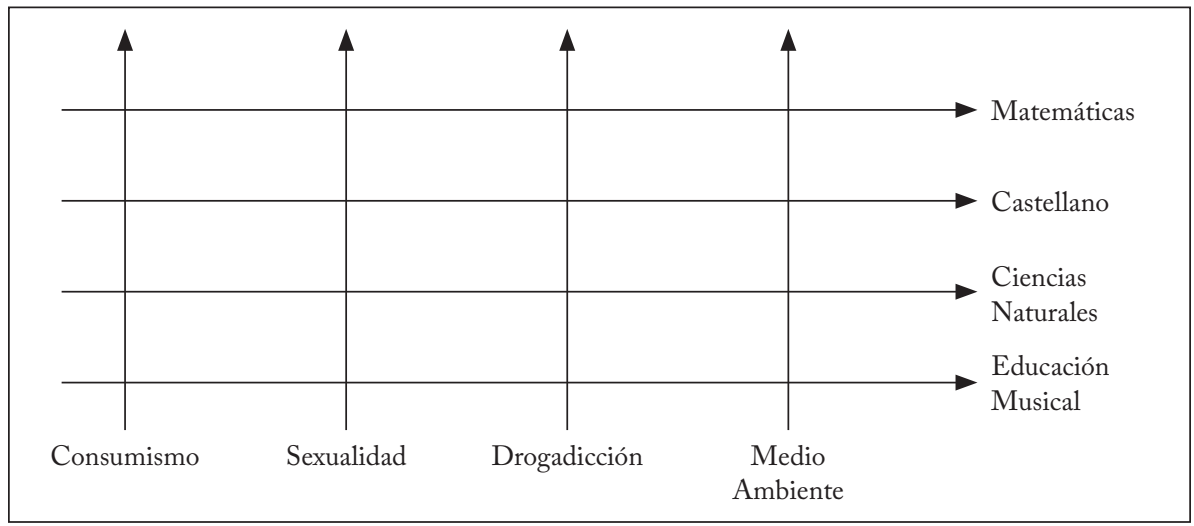

Gráfico 2 - Currículo horizontal

Elaboración de los autores. 
Si bien las naciones sudamericanas apostaron por el modelo transversal - como también lo hicieron muchos países de Europa y de las otras regiones de América y el mundo - en no todas tal modelo tiene un carácter imperativo. También sucede que de estado a estado la transversalidad no es llevada al aula bajo la misma lógica y bajo los mismos argumentos, es decir, los colegios que acogen este modelo tienen la posibilidad de entender el contenido de cada tema bajo sus propias concepciones y de trabajarlos de la forma que mejor les parezca. Por ejemplo, una escuela o liceo puede tratar el aspecto socio-moral de estos temas de manera unilateral (define todo lo que es bueno o malo para los estudiantes), es decir, intenta inculcar en sus alumnos la moral que estima conveniente, o bien, permite la participación de los alumnos, pero es una participación "restringida", i.e., que el alumno llegue a comprender por sus propios medios lo que el colegio desea que comprenda y practique de las temáticas transversales. Por el contrario, otro colegio puede entender que el arraigamiento de una cierta moral es un desarrollo individual, y sirviéndose de estos temas desea posibilitar la construcción de una identidad moral autónoma.

Para que el modelo de transversalidad concrete los objetivos que se propone, nosotros abogamos por la práctica de dos ideas. La primera, es que los centros educativos antes de proponerse educar al sujeto mediante el conocimiento científico deberían pensar en cómo estos pueden ser enseñados en consideración de la moral humana, inserta esta en los aspectos del día a día, amplios y cotidianos, conocidos o inadvertidos, independiente de su naturaleza, y que pueden ser retratados a partir de temáticas transversales. La segunda idea, que tomamos de Josep Puig y Xus Martín (1998), es que los colegios — guiados o el uso de la didáctica transversal — deberían posibilitar la construcción de "personalidades morales", esto es, hombres y mujeres cuyo télos es el Bien y la felicidad, colectiva e individual, a partir de mores que son anhelados por la cultura o el grupo al que pertenecen y/o se identifican. Bajo este principio, estos autores sostienen que una excelente alternativa para educar la moralidad del sujeto, o de favorecer su perfeccionamiento, es a través de la discusión colectiva de temas, ideas, o conflictos morales. Señala Puig: "el primer paso en la construcción de la personalidad moral es contar con situaciones de controversia o conflicto moral" (Puig, 1996, p. 172). Aquello, porque la apropiación de una cierta moral no es una cuestión que viene de antemano ni es natural, puesto que se llega a poseer, entre otras cosas, en tanto el ser se relaciona dialécticamente con sus congéneres.

Para este modelo la adquisición de la moral consiste en un trabajo de elaboración individual, social y cultural, que se hace posible "mediante los procedimientos de deliberación y dirección moral que cada individuo va adquiriendo a lo largo de su desarrollo" (Puig, 1996, p. 71). En síntesis, este modelo se trata de una

construcción y reconstrucción personal y colectiva de formas morales valiosas. La moral ni está dada de antemano ni tampoco se descubre o elige casualmente, sino que exige un trabajo de elaboración personal, social y cultural. Por consiguiente, no se trata de una construcción en solitario ni tampoco desprovista del pasado y al margen de todo contexto histórico. Todo lo contrario: es una tarea influida socialmente que, además, cuenta con precedentes y con elementos cul- 
turales de valor que sin duda contribuyen a configurar sus resultados. Pero, en cualquier caso, es una construcción que depende del sujeto. (Puig, 2001, p. 111)

$Y$ estas ideas posibilitan que entendamos otras cuestiones muy importantes: la idea que la moral es un fenómeno de construcción y la propuesta de llevar al colegio temas/situaciones/problemas con los que no se converja. Hacer de este ejercicio una práctica habitual, puesto que la no concordancia favorece que el sujeto adquiera, defienda o ceda ante los demás algunos modos de ver el mundo y de vivir en él; que, a partir de su relacionamiento dialógico, dialéctico, y afectivo con los otros, construya con autonomía su personalidad moral.

En síntesis, las temáticas transversales, cuando son encajadas en los contenidos de las distintas disciplinas o esferas formativas, deberían trabajarse a partir de situaciones moralmente conflictivas. En este contexto, por ejemplo, el profesor de ciencias naturales cuando enseña el aparato reproductor humano introduzca la problemática ética del asunto (por ejemplo, el desarrollo de la sexualidad, los embarazos precoces, etc.), sino que esta problemática sea discutida de tal forma que permita la confrontación de ideas diferentes.

\section{CONSIDERACIONES FINALES}

A veces la educación moral se entiende como una esfera más de la educación. Sin embargo, hemos podido argumentar que esta dimensión formativa es la propia educación, y en un doble sentido: es tanto su elemento medular como su fin último. En otras palabras, la educación de la moralidad es el nervio central del proceso formativo ya que atraviesa todos los ámbitos del conocimiento. $Y$ es su finalidad en el sentido del "aprender a vivir" en la esfera individual, privada y pública, i.e., ser-educado en la plenitud del concepto.

Hemos comprendido que el desarrollo de la personalidad moral del sujeto depende del contacto (y socialización) con los elementos que componen su cultura, v.g., familia, calle, escuela, amigos, deportes, arte, medios de comunicación. No obstante, la educación de la moralidad también depende del propio individuo, como una cuestión consigo mismo: auto-educarse como principio de autonomía.

En Sudamérica se llevan a cabo distintas prácticas para educar la moralidad, todas ellas, indiferente de sus distinciones, posibilidades y límites, tienen algo en común: promover el aprendizaje para la vida, sobre todo en lo que atañe la esfera social de la existencia, i.e., valores, reflexiones y prácticas morales para que los estudiantes se puedan desenvolver como futuros ciudadanos. La propuesta de desarrollar una educación(moral) a partir del modelo transversal es, a nuestro entender, la más precisa para concretar tal objetivo. Aquello, porque favorece que en todas las disciplinas y ámbitos del conocimiento la reflexión ética salga a la luz, i.e., tenga un espacio. Es en esta alternativa donde encontramos que la educación encuentra su sentido más profundo: educar la moralidad, antes que nada.

Por increíble que parezca, estamos en tiempos en donde aún la educación basada en contenidos sigue siendo un problema y no una ventaja: nos seguimos volcando mucho más a la enseñanza de materias específicas y al desarrollo de habilidades y técnicas que a la comprensión del mundo como un todo. 
Yendo más lejos, nos parece válido pensar que los temas transversales, trabajados especialmente a partir de dilemas morales o situaciones de conflicto, bien colaboran en el desarrollo de dos aspectos de relevancia para la construcción de sociedades más justas, de ciudadanos más participativos: pensar a partir del otro, reflexionar - y sentir - constante y colectivamente los problemas que aquejan a la sociedad y al mundo. Dicho de otro modo, hacer que los temas transversales el más importante elemento de las materias específicas -, favorezcan comprender el mundo como un todo y no apenas fragmentos aislados de él. Desde ahí, llevar las comprensiones al plano de la acción: que la escuela realmente colabore en la educación de ciudadanos participativos, justos, solidarios.

\section{REFERENCIAS}

Abbagnano, N. Diccionario de filosofía. México, DF: FCE, 2007.

Abbagnano, N.; Visalberghi, A. Historia de la pedagogía. México, DF: FCE, 1992.

Araújo, U. Temas transversais e a estratégia de projetos. São Paulo: Moderna, 2003.

Benjamin, W. Metafísica de la juventud. Barcelona: Paidós, 1993.

Brasil. Parâmetros Curriculares Nacionais. Brasília: MEC; SEF, 1997.

CHILE. Objetivos fundamentales y contenidos minimos obligatorios de la educación media. Decreto n. 220. Santiago: Ministerio de Educación de Chile, 1998.

Colombia. Lineamientos curriculares para el área de ética y valores humanos. OEI; Ministerio de Educación Nacional de Colombia, 1998. Disponible en: <http://www. oei.es/valores2/boletin6e.htm>. Acceso en: 28 agosto 2014.

Del Col, J. Diccionario auxiliar español-latino para el uso moderno del latín. Bahía Blanca: Instituto Superior Juan XXIII, 2007.

Dewer, J. Los principios morales que cimentan la educación. Madrid: Espasa Calpe, 1934. Fernández, O. et al. Eje transversal. "Valores" en la educación básica: teoría y praxis. Educere, v. 12, n. 40, 2008. Disponible en: <http://www.scielo.org.ve/scielo. php?script=sci_arttext\&pid=S1316-49102008000100008 $>$. Acceso en: 5 marzo 2018. Freire, P.; Betto, F. Essa escola chamada vida: depoimentos ao repórter Ricardo Kotscho. São Paulo: Ática, 1986.

Gadamer, H. Educar es educarse. Barcelona: Paidós Ibérica, 2002.

Hoyos, G.; Ruiz, A. Ciudadanias en formación. Bogotá: Civitas, 2008.

Hume, D. Investigación sobre los principios de la moral. Madrid: Alianza, 2006.

Jackson, P. W. La vida en las aulas. Madrid: Morata, 1992.

Kant, I. Sobre la pedagogía. Buenos Aires: Elaleph, 2000.

. Fundamentación de la metafísica de las costumbres. Madrid: Encuentros, 2003.

Kilpatrick, W. H. Educação para uma civilização em mudança. São Paulo: Melhoramentos, 1971.

La Taille, Y. A educação moral: Kant e Piaget. In: Macedo, L. (Org.). Cinco estudos de educação moral. São Paulo: Casa do Psicólogo, 1996. p. 135-176. 
La Taille, Y. Construção da consciência moral. São Paulo: UNESP; UNIVESP, 2012. Machado, N. Educação: projetos e valores. São Paulo: Escrituras, 2004.

Martín, X.; Puig, J. Sete competências básicas para educar em valores. São Paulo: Summus, 2010.

Martínez, M.; Tiana, A. Educación, valores y cohesión social. Ginebra: 2004. p. 2-21. TALLER 2: Calidad de la educación e inclusión social. Ponencia en la Cuadragésimo Séptima Conferencia Internacional de Educación. Disponible en: <http://www.ibe. unesco.org/International/ICE47/Spanish/Organisation/Workshops/Background\%20 at-2-ESP.pdf $>$. Acceso en: 10 jun. 2017.

Moreno, M. Temas transversais: um ensino voltado para o futuro. In: Busquets, M. D. et al. Temas transversais em educação: bases para uma formação integral. São Paulo: Ática, 1999. p. 19-59.

Oraisón, M. La transversalidad en la educación moral: sus implicancias y alcance. Montevideo: OEI, 2000. Disponible en: <http://www.oei.es/valores2/oraison.htm>. Acceso en: 28 agosto 2014.

Ortiz, J. M. P. La educación en valores y su práctica en el aula. Tendencias Pedagógicas, Madrid: Universidad Autónoma de Madrid, n. 8, p. 69-88, 2003.

Osorio, L.; Balbuena, C. Latinoamérica vista desde el paradigma eurocéntrico: un análisis de los textos escolares de historia universal. Revista Tiempo y Espacio, Caracas: Instituto Pedagógico de Caracas, v. 23, n. 60, p. 39-58, 2013.

PAYÁ, M. et al. Educación ética y en valores. Barcelona: Universitat de Barcelona, 2010.

Pérez de Cuellar, J. La nostra diversitat creativa. Informe de la Comissió Mundial sobre Cultura i Desenvolupament. Barcelona: Centro UNESCO de Catalunya, 1997. Perú. Diseño curricular nacional de educación básica. Lima: Ministerio de Educación República del Perú, 2005.

Puig, J. La construcción de la personalidad moral. Barcelona: Paidós, 1996.

. Construcción dialógica de la personalidad moral. Revista Iberoamericana de Educación, Madrid: OEI, n. 8, p. 103-120, 2001. Disponible en: <http://rieoei.org/ oeivirt/rie08a04.htm>. Acceso en: 7 jul. 2016.

Puig, J.; Martín, X. La educación moral en la escuela. Barcelona: Edebé, 1998.

Quintana, J. Pedagogía axiológica. La educación ante los valores. Madrid: Dykinson, 2005.

Quinteros, H. Curso de administración y gestión educativa. Iquique: Campvs, 2005.

Reboul, O. Filosofia da educação. São Paulo: Companhia Editora Nacional, 1986.

Romão, J. Pedagogias de Paulo III. Uberlândia: Editora Popular, 2005.

Rorty, R. Contingencia, ironía y solidaridad. Barcelona: Paidós, 1991.

SACristán, J. ¿Qué significa el currículum? Sinéctica, Tlaquepaque, México: Ediciones Morata, n. 34, p. 11-43, enero/jun. 2010.

Soто, D. Historiografía, eurocentrismo y universalidad en Enrique Dussel. Revista Ideas y Valores, Bogotá: Universidad Nacional de Colombia, v. 61, n. 148, p. 35-58, 2012. 
Torroella, G. Educación para la vida: el gran reto. Revista Latinoamericana de Psicología, Bogotá: Fundación Universitaria Konrad Lorenz, v. 33, n. 1, 2001.

VArgas, C. El aprendizaje a lo largo de toda la vida desde una perspectiva de justicia social. París: UNESCO. Serie de documentos temáticos sobre Investigación y Prospectiva en Educación, n. 21. Disponible en: <https://es.unesco.org/node/262744>. Acesso en: 24 jul. 2017.

ZARAYA, D. Os combinados em sala de aula: uma prática construtivista para a legitimação moral dentro da escola. 2013. Trabalho de Conclusão de Curso (Pós-Graduação em Ética, Cidadania e Valores na Escola) — Universidade de São Paulo, São Paulo, 2013.

\section{SOBRE LOS AUTORES}

Miguel Antonio Ahumada Cristi es doctor en educación y sociedad por la Universidad de Barcelona (España). Profesor de la Universidad Federal de la Integración Latinoamericana (UNILA).

E-mail: miguel.cristi@unila.edu.br

Xus Martín García es doctora en pedagogía por la Universidad de Barcelona (España). Profesora de la misma institución.

E-mail:xusmartin@ub.edu

Recibido el 6 de noviembre de 2016

Aprobado el 4 de julio de 2017 